\title{
LUIS CONTIER COMO CATALISADOR DE REDES: CLASSES EXPERIMENTAIS E RENOVAÇÃO DO ENSINO SECUNDÁRIO EM SÃO PAULO NAS DÉCADAS DE 1950 E 1960
}

DOI: http://dx.doi.org/10.1590/2236-3459/80603

\author{
Letícia Vieira' \\ 'Universidade de São Paulo (USP), São Paulo/SP, Brasil \\ Daniel Ferraz Chiozzinill \\ "Pontifícia Universidade Católica de São Paulo (PUC-SP), São Paulo/SP, Brasil
}

$\cos 80$

\begin{abstract}
Resumo
Nos debates educacionais ocorridos após o fim da ditadura Vargas, ganha relevo a temática do Ensino Secundário, visto como essencial para articular o processo de escolarização com o desempenho de ofícios, tarefas ou papéis sociais. Neste sentido, o presente artigo visa, a partir de noções como redes de sociabilidade e capital social, situar a figura do educador Luis Contier como um intelectual da educação que contribuiu, de forma pioneira, para a renovação do ensino público secundário no estado de São Paulo nesse espaço-tempo, via projeto das Classes Secundárias Experimentais. Para tanto, será dada ênfase à sua dimensão intelectual, elucidando as redes e instituições das quais participou, a partir da análise de fontes documentais de seu acervo pessoal.

Palavras-chave: intelectuais, ensino secundário, classes experimentais, renovação pedagógica.
\end{abstract}

\section{LUIS CONTIER COMO CATALIZADOR DE REDES: CLASSES EXPERIMENTAIS \\ Y RENOVACIÓN DE LA EDUCACIÓN SECUNDARIA EN EL ESTADO DE SAN PABLO EN LAS DÉCADAS DE 1950 Y 1960}

\section{Resumen}

Durante los debates sobre la educación, luego de finalizada la dictadura de Vargas, la temática Educación Secundaria gana importancia siendo percibida como esencial para articular el proceso de escolarización con el desempeño de oficios, tareas y papeles sociales. Este artículo busca, a partir de nociones como redes de sociabilidad y capital social, situar la figura del educador Luis Contier como un intelectual de la educación que contribuyó, de forma pionera, a la renovación de la educación pública secundaria en el estado de São Paulo en ese espacio-tiempo, vía proyecto de las Classes Secundárias Experimentais. Para ello, se dará énfasis a su dimensión intelectual, elucidando las redes e instituciones de las cuales participó, a partir del análisis de fuentes documentales de su acervo personal.

Palabras clave: intelectuales, educación secundaria, classes experimentais, renovación pedagógica. 


\title{
LUIS CONTIER AS A CATALYST OF NETWORKS: CLASSES EXPERIMENTAIS AND RENEWAL OF SECONDARY EDUCATION IN SÃO PAULO IN THE 1950S AND 1960S
}

\begin{abstract}
During the discussions about education right after Vargas dictatorship, Secondary Education topic gains importance, being seen as essential into the articulation of schooling process with the performance of occupation, tasks and social roles. The present article, based on notions such as networks of sociability and social capital, aims to situate the figure of educator Luis Contier as an intellectual of education who contributed, in a pioneering way, to the renewal of secondary public education in the state of São Paulo in this space-time, through a project of the Classes Secundárias Experimentais. To this end, emphasis will be placed on his intellectual dimension, elucidating the networks and institutions in which he participated, based on the analysis of documentary sources of his personal collection.

Keywords: intellectuals, secondary school, classes experimentais, pedagogical renewal.
\end{abstract}

\section{LUIS CONTIER COMME CATALYSEUR DE RÉSEAUX : CLASSES EXPERIMENTAIS ET RENOUVELLEMENT DE L'ENSEIGNEMENT SECONDAIRE À SÃO PAULO DANS LES ANNÉES 1950 ET 1960.}

\section{Résumé}

Dans les débats éducatifs qui ont eu lieu après la fin de la dictature de Vargas, est mis en évidence le thème de l'enseignement secondaire, essentiel pour articuler le processus de scolarisation avec la performance des métiers, des tâches ou des rôles sociaux. En ce sens, cet article a l'intention, à partir de notions telles que les réseaux sociaux et le capital social, à situer la figure de l'éducateur Luis Contier comme un intellectuel de l'éducation qui a contribué, de manière pionnière, au renouvellement de l'éducation publique secondaire dans l'État de São Paulo dans cet espace-temps, par le biais du projet des Classes Secundárias Experimentais Pour cela, l'accent sera mis sur sa dimension intellectuelle, en élucidant les réseaux et les institutions auxquels il a participé, à partir de l'analyse des sources documentaires de sa collection personnelle.

Mots-clés: intellectuels, enseignement secondaire, classes experimentais, renouvellement pédagogique. 


\section{Introdução}

pós vencidos os anos finais da década de 1940, período em que o Ensino
Secundário brasileiro ainda não havia sido integrado significativamente à
pauta de discussões educacionais, essa etapa da educação passa, finalmente, a ser debatida, à medida que emergem críticas que evidenciam a necessidade de sua reinvenção. Até esse período, a educação secundária permanecia como reduto do tradicionalismo pedagógico e norteava-se pela Lei Orgânica do Ensino Secundário de 1942, que the prescrevia uma cultura escolar marcada pelo retorno das humanidades e pela nacionalização autoritária. (DALLABRIDA, 2014). Esse maior debate, ainda que tardio, fora em boa medida fomentado pela ação de educadores vinculados à pedagogia escolanovista, signatários do Manifesto dos Pioneiros da Educação Nova e que, a partir de 1945, viram na reabertura democrática da sociedade brasileira a oportunidade para recolocarem suas convicções pedagógicas. Suas críticas colocavam em evidência, entre outras questões, a distância existente entre o que a escola tradicional oferecia ao seu público e o que a sociedade requeria em termos de desempenho de ofícios, tarefas ou papéis sociais, e o desinteresse dos alunos pelos estudos e pela escola demarcada pela utilização de métodos demasiadamente tradicionais - fatores apontados como os elementos responsáveis por uma derrocada no aproveitamento dos estudantes secundaristas nos anos 1950.

Nesse contexto de efervescência cultural, circulação de intelectuais e criatividade pedagógica, emergiram experiências como as Classes Secundárias Experimentais e os Ginásios Vocacionais, tendo sido estes últimos desenvolvidos a partir de um desdobramento de uma das Classes vinculadas a este primeiro ensaio: as Classes do Instituto Narciso Pieroni, da cidade de Socorro (SP). Cabe, nesse sentido, atribuir destaque à atuação de um dos intelectuais que atuaram de forma decisiva para a concretização e desenvolvimento destes ensaios de renovação do Ensino Secundário público do estado de São Paulo. Trata-se de Luis Contier, educador e intelectual que, imerso nesse debate que ocorria internacionalmente, buscava respostas para seus anseios de renovação do ensino secundário tradicional. Tendo retornado de curso sobre as classes nouvelles na França ${ }^{1}$, realizou, de forma pioneira, no Colégio Estadual Professor Alberto Conte ${ }^{2}$, instituição de ensino em que ocupava o cargo de diretor, uma tentativa efetiva de reinvenção do arcaico Ensino Secundário vigente. Desta feita se dão, a contragosto da legislação em vigor, que não permitia ensaios dessa natureza, os primeiros passos na direção da aplicação de métodos ativos nesse nível de ensino: inicia-se um trabalho com professores e alunos para introdução da metodologia ativa - um dos princípios das Classes Nouvelles -, e dá-se início à renovação metodológica.

\footnotetext{
1 Contier fora promovido em 1948 a diretor do Ensino Secundário e nomeado para dirigir o Instituto de Educação "Professor Alberto Conte" (BUZELLI FILHO, 1971, s. p.), localizado no bairro de Santo Amaro, cidade de São Paulo, e após a nomeação representou, em 1950, o Estado de São Paulo no Congresso de Educadores realizado na França, onde se discutiu a reforma de ensino recém-iniciada no contexto francês, no campo da experimentação. (PAI..., 1980). Logo depois, a convite do governo francês, ele compôs o primeiro grupo de brasileiros a realizar estágio no Centro Internacional de Estudos Pedagógicos (Ciep) de Sèvres (CONTIER, 1981), ali permanecendo por aproximadamente dois anos, período no qual realizou estudos a respeito da reforma do ensino que instituiu as chamadas Classes Nouvelles. (DESIGNAÇÕES..., 1965).

2 Nas fontes analisadas constam tanto a nomenclatura "Colégio Estadual Professor Alberto Conte", quanto "Instituto de Educação Professor Alberto Conte". Resta esclarecer com exatidão o ano em que a instituição recebe o status de "Instituto", o que não foi possível até o momento a partir das fontes a que se teve acesso.
} 
A partir da ação pioneira de Luis Contier, iniciam-se dois importantes movimentos: em primeiro lugar, divulga-se a experiência por ele realizada no Instituto e, a partir de sua repercussão, dá-se início ao processo de autorização das Classes Secundárias Experimentais, sendo emitidos os pareceres de autorização dessas experiências. Logo, dáse o segundo movimento, de amplo intercâmbio com o Centro Internacional de Estudos Pedagógicos (Ciep) e apropriação do modelo pedagógico da matriz de Sèvres por parte daqueles que buscavam promover esses ensaios renovadores no subcampo do ensino secundário paulista. Entre as instituições que se apropriaram dessa matriz está o Instituto Narciso Pieroni, de Socorro, onde instalou-se a primeira Classe Secundária Experimental oficial. A importância do estudo do ensaio pedagógico realizado nessa instituição dá-se, sobretudo, pelo fato de que tal experiência foi considerada o embrião dos chamados Ginásios Vocacionais, projeto experimental desenvolvido entre 1961 e 1970 e que contou com seis unidades, situadas nas cidades de Barretos, Batatais, Rio Claro, Americana, São Paulo e São Caetano do Sul. (CHIOZZINI, 2014). O "modelo" das Classes Experimentais de Socorro fora colocado em circulação e apropriado nos Ginásios Vocacionais pelas vias da ação de Maria Nilde Mascelani, que havia sido Orientadora Educacional na experiência realizada em Socorro e fora a principal idealizadora da ideia dos Vocacionais. Há, portanto, uma articulação entre a atuação de Contier e um processo de renovação do ensino secundário no período.

Nessa direção, acreditamos ser válido dar destaque a algumas questões. A primeira delas assenta-se no caráter transnacional deste estudo, por tratar-se de um processo de apropriação de pressupostos pedagógicos a partir da circulação e ação dos atores envolvidos na experiência. Entende-se, aqui, a circulação como um processo de "relações multidirecionais" (CARVALHO, 2009, p. 158), a partir do qual o conhecimento é apropriado e recebido de forma ativa por seus interlocutores. Buscar compreender 0 fenômeno de circulação de bens culturais, mercadorias e/ou informações leva-nos também à necessidade de compreender que o "local é persistentemente reconfigurado por influências distantes, por agentes, ferramentas e medidas padronizadas, e esclarecimentos conceituais". (LAWN, 2014, p. 127).

Bloch (1948, p. 142) já nos alertava sobre a necessidade de partirmos "os compartimentos topográficos obsoletos em que pretendemos encerrar as realidades sociais". Lawn (2014, p. 127), nessa mesma esteira, acrescentava que "a história da educação tem tratado seu objeto de estudo como se fosse naturalmente nacional e com fronteiras impermeáveis", não revelando "suas ligações transfronteiriças e transnacionais". Busca-se, portanto, percorrer os múltiplos caminhos traçados por esses atores, bem como dos saberes pedagógicos de que foram porta-vozes, e os quais não são, necessariamente, confinados às fronteiras nacionais, ainda que sempre reconfigurados pela dimensão social e política local. Interessa-nos, a partir dessa perspectiva, perceber como cada indivíduo neste caso, especificamente Luis Contier - apropriou-se dos bens culturais disponíveis nesses circuitos transnacionais. Os processos de rearranjo e apropriação da matriz de Sèvres no contexto brasileiro, movimento que fora iniciado por Luis Contier e posteriormente incorporado pela legislação educacional, devem ser compreendidos em sua natureza multidimensional e relacional (ROCKWELL, 2005), tecendo suas conexões, o que acaba, inevitavelmente, por levar-nos à vinculação com seus sujeitos e atores.

A possibilidade de observação dos processos de circulação e apropriação de 
modelos pedagógicos a partir do trânsito dos sujeitos envolvidos torna-se ainda mais interessante à medida que se nota que as missões e o intercâmbio de intelectuais franceses e brasileiros, principal meio de entrada da matriz da Classes Nouvelles no país, davam-se a partir do contato e das negociações promovidas por intelectuais brasileiros que, imbuídos de capital social, teciam uma rede de sociabilidade e, consequentemente, um discurso educacional favorável à concretização dessas experiências. (VIEIRA, 2015). Nesse sentido, a noção de "rede" revela-se uma profícua categoria de análise para leitura deste objeto.

Portugal (2007) realiza uma análise de rede - ou network analysis - que a aproxima da noção de capital social - tipo específico de capital gerado nas relações. A autora, apropriando-se de Lin (2001), compreende esse tipo de capital como um bem social produzido em virtude das conexões dos atores e do acesso aos recursos dessas redes de conexão ou do grupo de que fazem parte". (PORTUGAL, 2007). Pierre Bourdieu (1998, p. 67), define o capital social como um "conjunto de recursos atuais ou potenciais que estão ligados à posse de uma rede durável de relações mais ou menos institucionalizadas de interconhecimento e de inter-reconhecimento ou, em outros termos, à vinculação à um grupo". Essas redes de relações, por sua vez, funcionam a partir de ligações permanentes e úteis e fundam-se em trocas materiais e simbólicas "cuja instauração e perpetuação supõem o re-conhecimento dessa proximidade". (BOURDIEU, 1998, p. 67). Considera-se, concordando com Portugal (2007), que os estudos de Bourdieu, ao buscarem flagrar as desigualdades sociais, evidenciam que as redes não são um dado natural. Antes, são "construídas a partir de estratégias de investimento nas relações sociais, passíveis de serem utilizadas como fontes de benefícios". (PORTUGAL, 2007, p. 17).

Operacionalizando o estudo de redes sociais a partir da análise da morfologia dessas redes, Portugal (2007) propõe a identificação dos nós e laços que a constituem. Os nós, na perspectiva da autora, seriam "os elementos da rede, identificados pela relação que têm com o ego". Os laços seriam constituídos pelas relações entre os nós da rede e poderiam assumir características diferentes. Um critério fundamental seria a existência ou não de relações de parentesco e deveria ser levado ainda em consideração se os laços se constituem como positivos ou negativos, fortes ou fracos, e passivos ou ativos. A força dos dados é analisada a partir da duração da relação, sua intensidade emocional, intimidade, serviços recíprocos (GRANOVETTER, 1973 apud PORTUGAL, 2007) e multiplexidade, ou seja, pluralidade de conteúdos de troca existentes no laço. (DEGENNE; FORSÉ, 1994 apud PORTUGAL, 2007). De outra parte, os laços positivos são aqueles de identificação, através dos quais os autores se reconhecem como membros de uma entidade comum, enquanto os laços negativos são aqueles de diferenciação, a partir dos quais os indivíduos demarcam-se como pertencentes a entidades diferentes.

Evidencia-se, nesse sentido, o fato de que a rede de relações de Luis Contier ${ }^{3}$ exerceu forte influência sobre a circulação da matriz das Classes Nouvelles no campo educacional brasileiro, em especial no estado de São Paulo. Justifica-se, portanto, um maior investimento no sentido de compreender o alcance do capital social desse intelectual, uma vez que suas ações e relações refletem, também, as táticas de que lançou mão para possibilitar um maior "fluxo de recursos" - no caso em tela, recursos pedagógicos, tanto

\footnotetext{
${ }^{3} \mathrm{Em}$ algumas das fontes analisadas, o nome de Luis Contier se encontrava grafado com a letra Z. Mantevese, nesses casos, nas referências, a forma como estava escrito no documento. Contudo, ao longo do texto, foi respeitada a forma como o intelectual escrevia seu nome.
} 
materiais, quanto imateriais. (WASSERMAN; FAUST, 1999). A amplitude da rede de sociabilidades desse educador evidencia-se tanto a partir da análise de notícias publicadas à época, nas quais eram divulgados seus feitos e destacava-se seu envolvimento com os personagens das missões francesas, quanto das correspondências que compõem seu acervo pessoal. Nessas cartas e memorandos constam traços que permitem melhor visualizar os traços dessa rede.

Compreende-se que as redes de sociabilidades podem condicionar os resultados das ações dos indivíduos que dela fazem parte. Isso porque, nas redes, o fluxo da informação é facilitado pelos laços sociais que a compõem e que, uma vez acionados e colocados em posições estratégicas, fornecem aos atores informações úteis acerca das oportunidades e escolhas possíveis - informações que de outra maneira não estariam disponíveis. Ademais, os laços construídos nessas redes, a partir de relações de reconhecimento e inter-reconhecimento diante de determinado grupo, influenciam os agentes que têm um papel importante nas decisões e permitem o uso das relações sociais como "credencial", o que garante ao indivíduo o uso dos recursos disponíveis na rede da qual faz parte. (LIN, 2001a; LIN, 2001b).

Feito este panorama inicial, frisamos que realização de pesquisas no campo da história dos intelectuais nos obriga a uma discussão de cunho teórico e metodológico sobre os critérios para nomear um indivíduo como intelectual. Mesmo partindo de referenciais teóricos diversos, a dimensão empírica das pesquisas fatalmente leva o pesquisador a uma encruzilhada em que deve afirmar se um determinado sujeito histórico tem uma produção que sustente o predicado de intelectual. Essa caracterização muitas vezes sinaliza não apenas o status do sujeito histórico que está sendo investigado, mas sua pertinência como objeto de estudo. Nesse sentido, o presente buscará, inicialmente, lançar luz sobre um referencial teórico que pode ser utilizado em investigações que contemplem o profissional dedicado à escola pública, especialmente ligado ao nível de ensino denominado Ensino Secundário, e sua dimensão intelectual. Em um segundo momento, sem abandonar a dimensão teórica, dar-se-á foco ao principal objetivo do presente escrito, qual seja, lançar luz sobre a figura de Luis Contier como um intelectual da educação que deu contribuição significativa para a renovação do ensino público secundário do estado de São Paulo nos anos 1950 e 1960.

O recorte temporal do presente estudo compreende o período entre os anos 1950 e 1960, considerando-se o ano de 1951 o marco inicial, devido ao retorno de Contier de estágio em Sèvres e ao início da aplicação, por parte desse educador e intelectual, de métodos ativos no Colégio Estadual Professor Alberto Conte. De outra parte, os anos 1960 correspondem ao período final do presente estudo, no qual é possível notar, com maior clareza, as ressonâncias das ações de Luis Contier no campo educacional paulista. As fontes analisadas, por sua vez, correspondem a documentos do acervo pessoal do intelectual, o qual se encontra salvaguardado no Centro de Memória da Faculdade de Educação da Universidade de São Paulo. O acervo é composto por documentos pessoais do educador, contendo relatórios de experiências com as quais ele se envolveu ao longo de sua trajetória, diversos pareceres e relatórios de Classes e Escolas experimentais, textos, recortes de jornais, transcrições de entrevistas, livros e periódicos que lia e nos quais 
publicava, bem como manuscritos pessoais e cartas ${ }^{4}$.

\section{Instituições e intelectuais: breves contribuições teórico-metodológicas para o estudo de redes}

Em artigo intitulado "Intelectuais e história da educação em Portugal e Brasil", Justino Magalhães (2016) propôs um itinerário para investigação dos intelectuais que, como ele mesmo definiu, toma como referência três categorias apontadas como fundamentais na História Cultural, a partir de Chartier (1988): texto-documento, representação e intelectuais. O autor valeu-se também dos referenciais da História dos Intelectuais, de Sirinelli (2003), que articula dialeticamente ideias e intelectuais. Por fim, a partir da História intelectual de Vieira (2008) e Dosse (2003), enfatiza as noções de quadros conjunturais, a comparação de contextos e o entrosamento de temas e tônicas. Valendo-se do diálogo principalmente entre esses autores, teceu algumas considerações sobre os intelectuais da Seara Nova portuguesa e da chamada Escola Nova brasileira. O ponto de partida utilizado é a definição da educação como representação:

A educação pode ser representada de forma material e simbólica: a escola, a estatutária, a pintura, a escrita, a utopia. A epistemologia e a ciência da educação constituem sistemas de representação. No plano epistêmico, a ciência da educação é uma constelação de domínios científicos - as ciências da educação. No plano (in)formativo e de formação, a educação envolve as noções de programas, currículos, unidades curriculares, planos didácticos; no plano aprendente, envolve teorias, modos de aprendizagem, praxeologias. Também os materiais didácticos, os aparelhos de laboratório, as sequências de estamparia ou de mapas remetem para sistêmicas de diversa natureza. Nos planos descritivo e narrativo, a representação da educação inclui a escrita e outras manifestações materiais, simbólicas, discursivas. Como representação, a escrita da educação comporta fórmulas, pragmáticas, diferentes tipos e modalidades de discurso. (MAGALHÃES, 2016, p. 302).

Dada essa complexidade, propõe como questão fundamental um olhar sobre o processo de conversão da realidade educativa em objeto epistêmico, dotado de historicidade. Nesse processo, ganha relevo a definição do conceito de intelectual e da categoria de intelectuais, que são os sujeitos que configuram e demarcam o campo educacional, assegurando a relação entre educação e sociedade. Nesse sentido, afirma:

O intelectual constitui um conceito que pode ser trabalhado enquanto categoria epistêmica com educabilidade e historicidade. Tomados como categoria, os intelectuais funcionam como unidade de representação, confluindo em determinados momentos e em determinados gestos e tipos de afirmação (por exemplo, um manifesto, uma convenção). Todavia, dentro do campo da educação, os intelectuais cumprem funções e assumem significados estatutários e papéis diferenciados e, por vezes, hierárquicos. Os princípios da educabilidade e da

\footnotetext{
4 À época da consulta, nos anos 2016 e 2017, o acervo estava em fase de organização, de maneira que o Centro de Memória da Faculdade de Educação da Universidade de São Paulo (CME-USP) não contava ainda com um documento de catalogação definitiva destas fontes. Uma parcela do acervo, composta de 325 documentos doados pelo próprio Luís Contier ao Serviço de Biblioteca e Documentação da Faculdade de Educação da USP para integrar o Projeto "Memória Educacional", já estava devidamente organizada. Os demais documentos, doados diretamente pela família do intelectual após seu falecimento, haviam passado apenas por uma primeira higienização, onde foi realizada a retirada de grampos de metal e outros materiais que pudessem danificar o material. De todo modo, o acervo foi disponibilizado para consulta e se teve acesso às caixas com numeração provisória do Centro, além dos livros que compunham sua biblioteca pessoal.
} 
historicidade cumprem-se porque há dialéctica interna, há relação ao exterior, há documentação histórica, há frequentemente ensejo à (re)significação. (MAGALHÃES, 2016, p. 304).

Por esse motivo, o autor aponta que os arquivos de instituições, relatórios de experiências e programas educativos não contemplam as ideias e os intelectuais em si, mas apenas estes como agentes ou sob a modalidade de efeméride. Tais testemunhos escritos devem ser vistos como produtos que trazem consigo as ações que os antecederam, os agentes que os realizaram e os papéis que cabem a cada um deles. Magalhães propõe uma hierarquia entre os intelectuais a partir de fenômenos ou movimentos educativos historicamente determinados:

Tudo se passa como se os intelectuais "maiores" projectassem e configurassem determinadas ideias, trabalhando a escrita e fomentando a socialização e a constituição de uma opinião generalizada. Em torno deles e desse movimento inicial, há, em regra, grande adesão, ainda que a coesão de grupo seja, por princípio, muito tênue. O efeito de inovação e a capacidade de persuasão fazem do acto inicial um acto fundante e um gesto de grande abundância e um gesto de grande abrangência. A vulgarização e a normalização ficam a cargo de intelectuais orgânicos (fazedores e organizadores), numa convergência programática de maior coesão. Este segundo grupo tende a ser reduzido e a estruturar-se através de discursos, dispositivos e tempos de acção tecnicamente eficazes. Acresce, por fim, uma terceira vaga de intelectuais, que intenta conformar, implementar e consolidar as mudanças. Fazem-no frequentemente através de ondas sucessivas. Esta hierarquia ganha consistência na genealogia que inclui a combinação de diferentes tipos e diferentes tempos de acção e que tem associada uma diferenciação de estatutos e papéis. Assim se consagra uma hierarquia de intelectuais. A situação tende a ser complexa. Num mesmo grupo de intelectuais estão já frequentemente inseridos os diferentes tipos. É a intelectualidade, enquanto consciência centrípeta, que assegura o compromisso e a representação como conjunto. O capital simbólico de que os intelectuais são portadores parece variar com a arte de dizer: idealizar, conceptualizar, programar, realizar, relatar. (MAGALHÃES, 2016, p. 307).

Buscando uma figura que ilustre essa proposição, é possível dizer que os intelectuais produzem um eixo de representações da educação que, ao ser constituído, passa a exercer uma força centrípeta (o exercício da intelectualidade) em torno do qual outros sujeitos se articulam, mais ou menos próximos segundo sua condição. Nesse sentido, a partir das proposições de Magalhães (2016), podemos construir uma representação gráfica intitulada "A espiral da intelectualidade na educação5":

\footnotetext{
${ }^{5} \mathrm{O}$ modelo espiral como representação das proposições de Justino Magalhães foi pensado a partir do artigo intitulado "A espiral da cultura científica" (VOGT, 2012), no qual o autor faz uma leitura da relação entre arte e ciência e oferece um modelo para mapear e investigar as iniciativas e pesquisas situadas no âmbito do campo da divulgação científica. A articulação entre as proposições de Magalhães e Vogt demandam uma reflexão maior que não cabe no presente texto.
} 


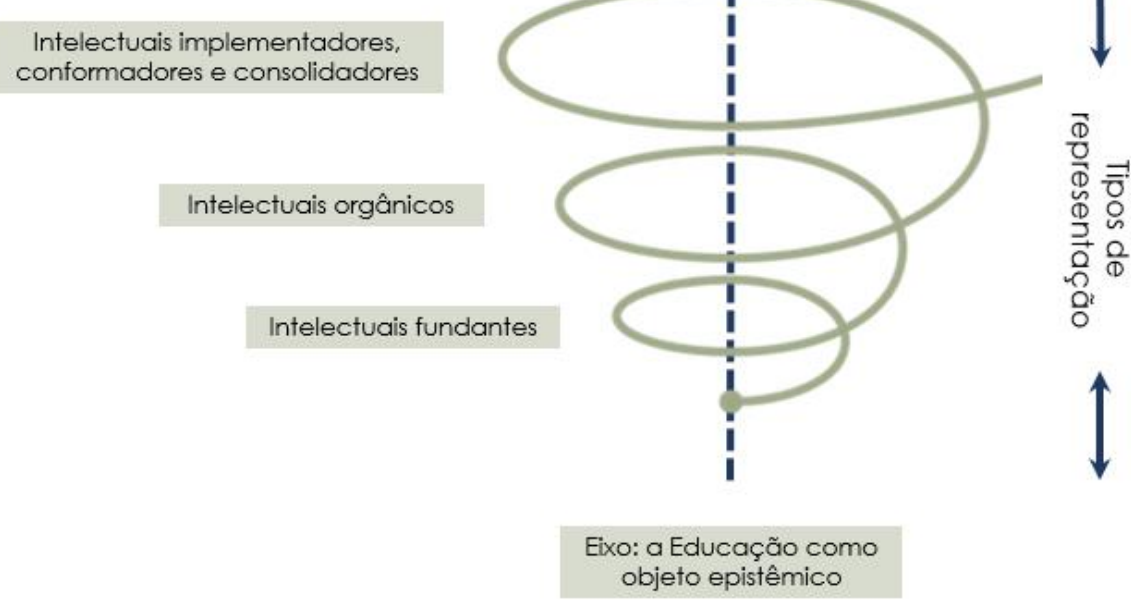

Figura 1 - Espiral da intelectualidade na educação.

Fonte: Elaboração dos autores.

O eixo em torno dos quais os intelectuais se orientam e estão hierarquizados é a educação como objeto epistêmico. As redes com as quais eles se articulam, com sua historicidade e educabilidade próprias, interferem diretamente no tipo de representação que desenvolvem. Nesse sentido, entendemos que os sujeitos podem estar em uma maior ou menor proximidade entre si na espiral, fazendo com que ela se comporte como uma "mola" que pode se comprimir ou expandir, levando as representações desses sujeitos, em uma situação hipotética, a estarem sobrepostas e a espiral "chapada". A hierarquia entre os intelectuais, sua respectiva denominação, no entanto, dá-se na prática do historiador, pois "a externalidade ao objeto faz dos intelectuais a representação e o paratexto, ficando comprometida e sublimada a hierarquia". (MAGALHÃES, 2016, p. 307). Sendo assim, segundo Magalhães (2016), somente a análise do historiador, feita a posteriori, pode revelar quais intelectuais podem ser nomeados em cada um dos três níveis.

Talvez uma das maiores dificuldades dos historiadores seja dedicar-se a investigação de intelectuais e produções situados hierarquicamente em níveis inferiores, muitas vezes vistos como meros "aplicadores". Libânea Xavier (2016) relata uma equação para o problema a partir da diferenciação que Jean François Sirinelli (1996) faz entre intelectuais criadores de uma cultura e os mediadores culturais, que seriam difusores de uma cultura constituída por outrem. Ao se dedicar a investigação da figura de João Roberto Moreira, que, juntamente com Jayme de Abreu e capitaneados por Anísio Teixeira, ocupou postos-chave na hierarquia educacional dos anos 1950 e 1960, a pesquisadora assim relata algumas de suas conclusões:

Nossas pesquisas sugeriam que as ações e produções textuais desses educadores não exerceram impacto compatível com a estrutura institucional e a rede de sociabilidades que as apoiava, tendo em vista: 1) o caráter extremamente técnico de suas narrativas; 2) A filiação prévia e integral aos postulados da Escola Nova, a ponto de produzir análises que, antes de descrever e tentar compreender a situação do ensino nas escolas observadas, desqualificava qualquer prática pedagógica que destoasse desses postulados; 3 ) o fato de a produção deles se enquadrar em uma literatura de transição, produzida num tempo em que os cânones acadêmicos começavam a se firmar em nosso país, distinguindo a produção universitária das 
publicações de caráter ensaístico ou produzidas no âmbito da burocracia estatal que, paulatinamente, foram desqualificadas como produtos culturais de baixo valor simbólico em contraposição acadêmica. (XAVIER, 2016, p. 472).

Posteriormente, Xavier descreve uma pesquisa (DANIEL, 2009) que caracterizou João Roberto Moreira como intelectual, considerando suas contribuições para além das posições burocráticas que ocupou, uma vez que replicou e difundiu princípios do grupo do qual fazia parte por meio de instituições de ensino e cultura que integrou. Também articulou projetos com redes políticas e de intelectuais a partir de movimentos de alcance regional e nacional. No entanto, a autora reafirma sua caracterização de Moreira como mediador cultural, já que suas ações o caracterizam como um difusor de métodos de ensino e gestor de escolas segundo os preceitos escolanovistas, "não se preocupando propriamente com a criação de novas metodologias e abordagens do processo pedagógico mas, sim, com a repercussão de um dado modelo". (XAVIER, 2016, p. 473).

Retornando ao modelo proposto por Justino Magalhães, acreditamos que a caracterização de um indivíduo como intelectual do campo da educação implica uma investigação que articule dois processos relacionados entre si e que efetivamente permitam caracterizar um intelectual. O primeiro deles é o processo de constituição e expansão das redes com as quais se articulou, dando destaque para sua filiação institucional. O segundo é a operação que o indivíduo desenvolve na constituição da educação como objeto epistêmico, o que efetivamente o caracteriza como educador. Nesse sentido, no âmbito da história dos intelectuais, vale retomar a velha metáfora de abrir a caixa preta da escola ${ }^{6}$, dando destaque a sujeitos que compõem uma rede até então pouco investigada: a chamada comunidade escolar, composta por pais, professores, diretores e alunos, na qual efetivamente é possível aferir uma inovação de metodologias e abordagens. No caso específico dos intelectuais que se projetaram nos anos 1950 e 1960, vale recuperar a intencionalidade das políticas desenvolvidas naquele período que almejaram alçar o professor a um novo estágio de atuação, superando a figura de mero aplicador ou difusor. Os "usos criativos" dos quais nos falou Michel de Certeau, não eram apenas inerentes ao jogo de táticas e estratégias do período, mas foram institucionalmente fomentados pela tônica das políticas educacionais. Vale recuperar a assertiva de Anísio Teixeira (2017, p. 130), publicada em 1957:

Será o novo professor que irá dar consistência e sentido às tendências de popularização da educação primária e do primeiro ciclo da escola média; que irá tornar possível e eficiente o curso de colégio (segundo ciclo da educação média), com suas preocupações de dar cultura técnica, cultura preparatória ao ingresso na universidade e cultura geral de natureza predominantemente científica e que irá preparar a transformação da universidade para as suas novas funções de introduzir a escola pós-graduada para a formação dos cientistas e a formação do magistério, tendo em vista as transformações em curso no sistema escolar, sem esquecer que Ihe caberá, inevitavelmente, uma grande responsabilidade na difusão da nova cultura geral, que a atual fase de conhecimentos humanos está a exigir.

A leitura sobre o quadro contextual, portanto, adverte-nos para olharmos de

\footnotetext{
${ }^{6}$ Sobre como essa perspectiva esteve presente na história da educação brasileira, ver: FARIA FILHO, Luciano Mendes; GONÇALVES, Irlen Antônio; VIDAL, Diana G.; PAULILO, André Luiz. A Cultura Escolar como categoria de análise e como campo de investigação na história da educação brasileira. Educação e Pesquisa, SP, v. 30, n. 1, p. 139-159.
} 
maneira atenta alguns dos sujeitos que se destacaram no campo da educação a partir dos anos 1950. Além das proposições de reinvenção da figura do professor, já bastante investigadas no âmago do ideário escolanovista, ganha relevância o processo de reinvenção do ensino secundário, dos sujeitos que ali se destacaram, e a circulação transnacional das ideias pedagógicas, criando redes que procuraremos elucidar adiante.

\section{Luis Contier como catalisador de redes: uma análise do surgimento das Classes Secundárias Experimentais a partir das redes de sociabilidades de um ator pioneiro}

O modelo pedagógico aplicado nas Classes Nouvelles buscava adaptar a pedagogia à renovação e à democratização do ensino, visando a formação de uma geração afinada com esses ideais. Nessa direção, a educação secundária deveria não mais voltarse para aqueles indivíduos advindos de meios sociais abastados, mas para a população geral, formando alunos para a vida e o trabalho. Tendo em vista esse objetivo, o professor passa a ganhar um diferente enfoque, devendo participar de todos os trabalhos e sustentar a equipe, colocando-se como um ser acessível a todos os alunos e preenchendo as lacunas que porventura existissem, não mais ocupando, então, uma função catedrática. Ensaiouse também, a partir da coordenação de disciplinas, a quebra da ideia de conteúdos disciplinares como conteúdos estanques, passando estes a figurarem como instrumentos de formação, e inseriu-se a realização de trabalhos manuais. Buscou-se ainda, com a prática de Estudo do Meio, que os alunos adquirissem noção de espaço e tempo, identificando seu papel na sociedade em que viviam. A proposta era a de que essas práticas, articuladas, atuassem em prol da supressão da hierarquia no ambiente escolar. Complementava-se por fim este método, na experiência francesa, com a atuação de uma psicóloga, disponível na instituição em tempo integral, que desempenhava atividades no sentido de auxiliar o bom andamento da relação entre aluno, família e escola. Em pesquisa anterior (VIEIRA, 2015), atestou-se que, exceto no que se refere à presença de um profissional da área de psicologia, demanda que no Brasil fora suprida pelo setor de Orientação Educacional, os pressupostos pedagógicos das Classes Nouvelles foram apropriados como um todo na experiência desenvolvida por Contier, guardadas as limitações devidas às possibilidades legais e financeiras da instituição.

Em entrevista, Contier $(1981)^{7}$ destaca o fato de que as classes nouvelles repercutiram largamente no ensino secundário paulista. Nesse sentido, frisa-se que se considera esse educador, no presente escrito, uma das principais chaves para a ampla divulgação, repercussão e apropriação dessa experiência francesa no Brasil e, em especial, no estado de São Paulo. Assim como as ideias e apropriações de Luis Contier repercutiram nas práticas efetivadas nas Classes Secundárias Experimentais do estado de São Paulo, sua rede de relações permeou o projeto dessas classes e exerceu peso sob sua estruturação e desenvolvimento. Essa centralidade do educador para o processo de circulação e apropriação em marcha à época deve-se também à sua vinculação à uma rede

\footnotetext{
${ }^{7}$ Entrevista localizada no acervo pessoal da educadora e intelectual Maria Nilde Mascellani, salvaguardado no Centro de Memória da Educação da Universidade de São Paulo, e que contém, assim como o acervo de Luis Contier, fontes relacionadas às experiências de renovação do Ensino Secundário em São Paulo nos anos 1950 e 1960 (Ginásios Vocacionais e Classes Experimentais, por exemplo), bem como documentos relacionados à trajetória de Maria Nilde. A referida entrevista não continha identificação quanto ao entrevistador, apenas mencionava o sujeito entrevistado, Luis Contier.
} 
de sociabilidades favorável à difusão da experiência. Contier ocupava a posição de "intermediário entre o governo francês e as entidades culturais e educacionais do Brasil", conforme atestam notícias publicadas à época (NOTÍCIAS SOBRE A VINDA..., 1968), e agiu de forma a movimentar essa rede em favor de seus objetivos, mobilizando de forma decisiva os volumes de capital de notoriedade intelectual e de capital social (BOURDIEU, 2013) e possibilitando a colocada de seu projeto de renovação do secundário em marcha. Nesse sentido, tomando como marco inicial desse processo de circulação de matriz pedagógica a estada do intelectual no Congresso de Educadores em 1950, e tendo seu vínculo com autoridades pertencentes ao campo educacional francês sido estreitado a partir da realização de estágio no Ciep de Sèvres, o educador impulsionou a circulação, no Brasil, mas especialmente no Estado de São Paulo, das discussões advindas daquele contexto que havia recentemente passado por reforma educacional.

Vieira (2015), ao descrever a experiência realizada no Colégio Estadual Professor Alberto Conte e a implantação do projeto das Classes Secundárias Experimentais a partir da emissão dos pareceres n. 31/58 e 77/58 da Consultoria Jurídica do Ministério da Educação e Cultura e do Decreto n. 35.069 do Departamento de Educação do Estado de São Paulo, evidencia táticas das quais o educador lançou mão para tornar possível a efetivação do projeto dessas experiências no contexto brasileiro dos anos 50 do século XX. Entre tais táticas, ganham destaque a mobilização de seu capital social e as ações para fazer circular, no contexto brasileiro, pelas vias de publicações em periódicos e oferecimento de cursos e organização de missões pedagógicas, a matriz pedagógica das Classes Nouvelles. Observou-se, neste estudo, que a rede de relações de Luis Contier teria sido decisiva não só para o surgimento e legalização das Classes Experimentais no estado de São Paulo, mas para a instalação de outras classes dessa natureza nas escolas públicas do estado.

As primeiras Classes Secundárias Experimentais oficiais, instaladas no Instituto Narciso Pieroni, foram inauguradas a partir da participação de Lygia Furquim Sim, diretora da instituição, na Primeira Jornada de Diretores, evento em que Contier foi convidado a divulgar a experiência que vinha desenvolvendo no Colégio Estadual Alberto Conte. A proximidade de Furquim com a metodologia das Classes Nouvelles devia-se também a seu contato com conferências ministradas no Brasil por Mme. Edmeé Hatinguais, Inspetora Geral do Ensino na França e Diretora Geral do Centre International d'Etudes Pédagogiques, bem como ao seu estágio realizado em Sèvres no ano de 1956, ambas experiências inscritas no círculo de iniciativas para circulação da matriz pedagógica de Sèvres no contexto brasileiro, das quais Contier era um dos principais âncoras. Ademais, deve-se atribuir a devida importância à sua posse na direção do Departamento de Educação do Estado de São Paulo no ano de 1958, fator que atuou como elemento de peso em relação à autorização desses ensaios pedagógicos.

Entre as correspondências que compõem o acervo de Luis Contier, chamam atenção aquelas trocadas com padre Pierre Faure, intelectual ligado à matriz de renovação católica apropriada pelo Ensino Secundário brasileiro. (AVELAR, 1978). Em uma dessas correspondências, datada de abril de 1963, Faure responde a um convite realizado por Contier e reforçado por reverenda mère Isabel Sofia, père Alonso, père Lafra e Mme. Mercie, para que fizesse viagem ao Brasil. Devido às inúmeras cartas que recebera, o intelectual católico decidiu, após realizar viagem ao Rio de Janeiro julho daquele ano, visitar 
também a cidade paulista, atendendo ao pedido de Contier. A relação entre o educador e Pierre Faure evidencia, em boa medida, o fato de que a circulação das matrizes pedagógicas francesas no Brasil não se deu através de um processo de polarização entre ensino laico e católico, mas por meio de um único movimento de transnacionalização dessas matrizes, que contava com a interlocução dos principais agentes de cada uma delas e que sinaliza um movimento de apropriação católica da Escola Nova.

As ações de Contier para promoção da circulação dessas matrizes no cenário educacional resultaram também na criação de uma filial do Centre International d'Études Pédagogiques no Brasil, denominado Centro de Estudos Pedagógicos de São Paulo e sediado no Centro Regional de Pesquisas Educacionais "Prof. Queiroz Filho". Essa filial, cujos trabalhos foram iniciados em 13 de julho de 1965, tinha por objetivo o estabelecimento de intercâmbio pedagógico com o Ciep de Sèvres e as instituições brasileiras que promoviam renovação do ensino. Pretendia-se difundir no Brasil as experiências realizadas em Sèvres, bem como dar visibilidade, na França, às experiências brasileiras (TERMO..., 1965). Faziam parte do grupo ligado ao Centro os professores Laerte Ramos de Carvalho, à época diretor do CRPE-SP, Luis Contier, ligado à Divisão do Ensino Secundário e Normal do Departamento de Educação de São Paulo, Mme. Collete Itourdzè ${ }^{8}$, conselheira pedagógica do Centro de Estudos Pedagógicos de Sèvres, Heládio Gonçalves Antunha, coordenador de divisão no CRPE-SP, Maria José Garcia Werebe, professora de Orientação Educacional do Departamento de Educação da Faculdade de Filosofia da USP, Luis Carranca, jornalista, Julieta Silveira Leite, coordenadora das Classes Integradas do Colégio de Aplicação da USP, Silvia Magaldi, instrutora da cadeira de Metodologia Geral de Ensino na Faculdade de Filosofia da USP, Flora de Barros, chefe do Serviço de Documentos e Intercâmbio do CRPE-SP, e alguns outros intelectuais ligados ao CRPE e à faculdade de Filosofia, Ciências e Letras da USP. Por outro lado, ainda que contasse com um corpo profissional de peso, é importante mencionar que o livro de Atas do Centro registrou uma única reunião, o que torna questionável o êxito da proposta.

Contier mantinha interlocução frequente com o Consulado Geral da França, em São Paulo, correspondendo-se com membros dessa organização, e, até os anos 1970, correspondia-se também frequentemente com o Centre International d'Études Pédagogiques - nessa época já sob direção do adjunto A. Janicot. A principal finalidade desses contatos era a organização de cursos a serem realizados no Brasil. Destaca-se, aqui, de imediato, a função de polarização ${ }^{9}$ ocupada por Contier, uma vez que desempenhava o papel de catalisador da relação com autoridades e centros de estudos franceses, mediando os laços estabelecidos entre os diferentes membros que passavam a fazer parte da rede. Deve-se atribuir também destaque ao contato do educador com Jean Piaget, importante intelectual cuja interlocução pode auferir-se a partir da presença de algumas correspondências trocadas entre ambos, a maior parte delas tratando de convite por parte de Contier para que Piaget visitasse o Brasil. A proposta, por sua vez, é aceita pelo intelectual, mas, por infortúnio, após agendada a vinda, o mesmo envia carta à Contier expondo situação que o impediria da visita e declarando admiração pelo trabalho e figura

\footnotetext{
8 Nome encontrava-se parcialmente ilegível na ata.

9 Portugal (2007) denomina "polarização" um tipo específico de propriedade morfológica de uma rede, na qual os atores a ela pertencentes desempenham um papel de "catalisadores de relações", ou seja, medeiam os laços estabelecidos entre os diferentes membros da rede.
} 
desse último. Afirma ele:

En vous exprimant une fois de plus ma très grande reconnaissance pour les projets que vous aviez et pour le caractere si amical de votre invitation, je vous pri, mon cher Collègue, de me pardonner et de croire à mes sentiments bien cordiaux. (PIAGET, 1973).

A extensão da rede de relações de Contier, para além de situá-lo como sujeito bem relacionado no campo educacional francês e brasileiro, atua como indicador do volume de seu capital social, uma vez que, segundo Bourdieu (1998, p. 67),

o volume do capital social que um agente individual possui depende então da extensão da rede de relações que ele pode efetivamente mobilizar e do volume do capital (econômico, cultural e simbólico) que é posse exclusiva de cada um daqueles a quem está ligado.

Logo, por relacionar-se com sujeitos de prestígio nos campos a que pertenciam, Contier acaba por agregar capital social e simbólico aos volumes de capital já por ele acumulados. No que se refere às propriedades morfológicas de sua rede, na perspectiva de Portugal (2007), destaca-se sua ampla dimensão, uma vez que envolvia diversos sujeitos de campos educacionais de diferentes países, uma densidade considerável, tendo em vista que, ainda que tivesse contato limitado com essas autoridades, possuía prestígio junto à elas ao ponto de conseguir obter vantagens para o desenrolar de seu "projeto de renovação educacional", polarização inquestionável, conforme já aqui destacado, e sobreposição de papéis, pois ocupava diversos espaços e tinha diferentes afazeres, simultaneamente, nessa rede.

Estando em contato constante com autoridades pertencentes a campos educacionais de outros países, Contier acaba por ter acesso ao arsenal teórico - matrizes teóricas, discursos, ideários - que se encontrava em circulação nesses espaços sociais e que tinha, na voz dos intelectuais, um espaço de enunciação. A imprensa periódica, nessa relação, figura como catalisadora para aquelas informações em fluxo na rede, ou seja, como uma das formas de divulgação e circulação das ideias dos educadores envolvidos em projetos de renovação do ensino que surgiram no contexto internacional, tornando possível a compreensão de iniciativas locais e configurações específicas da cultura escolar dessas experiências. Contier dispunha, em seu acervo pessoal, de diversos exemplares de periódicos de circulação mundial, sobretudo franceses, que tratavam do movimento da Escola Nova e da metodologia ativa, entre eles exemplares de Cahiers pédagogiques, propriedade do movimento pedagógico Fédération des Cercies de Recherche et d'Action Pédagogiques e cujos presidentes de honra eram Gustave Monod e Edmée Hatinguais; do periódico do Institut Pédagogique National, ligado ao Ministério de Educação Francês; da revista L'Éducation nationale, do Comité Universitaire D'Information Pédagogique; da revista Avenirs, e da revista Pedagogie: éducation et culture, do Centre D'études Pédagogiques.

Em sua relação com esses periódicos, o intelectual figura em duas distintas posições. A primeira, na qual se situa como leitor, pode ser auferida a partir das marcas de leitura deixadas pelo educador, pois, não bastasse a presença desses escritos no acervo pessoal de Contier - o que, por si só, não nos permitiria atestar a apropriação do escrito por parte do leitor -, é possível perceber, nesses periódicos, indicações de seus usos. Esses 
"registros do caminho do leitor pelas páginas", denominados marginalias (CUNHA, 2006, p. 03), permitem-nos apreender os assuntos aos quais Contier destinava maior atenção, bem como os sujeitos a quem pertenciam as produções às quais atribuía maior importância. Tais marcas contribuem para a análise dos saberes que sustentavam suas práticas nas Classes Experimentais Secundárias, "como formador de imaginários e subjetividades que carregam em si as marcas de um tempo". (CUNHA, 2006, p. 02).

Em exemplar de Pedagogie, Education et Culture, Contier assinala, logo na capa, a existência de artigo publicado por Pierre Faure a respeito das Classes Experimentais Brasileiras. No interior do texto, destaca trechos em que o intelectual católico afirma que graças ao decreto que autorizava as Classes Experimentais e à Lei de Diretrizes que o sucedera, ambos autorizando a organização escolar democrática, as experiências educacionais flexíveis vinham se multiplicando no Brasil. (FAURE, 1963, p. 735). Sublinha, ainda, pontos nos quais Faure menciona o fato de as realizações de instituições de São Paulo terem atraído muitas visitas, provocando a demanda por novos encontros, cursos e treinamentos, de maneira que se desenvolveu um curso de aperfeiçoamento didático, com aulas e workshops, e, por demanda do secretário da Educação do estado, realizou-se também sessão de formação reunindo os professores do ensino público. (FAURE, 1963, p. 736). Vale mencionar que, provavelmente, por saber-se autor desses feitos, Contier conferia maior importância a tais trechos da fala do intelectual. Ressaltamos, ainda, que a presença de um intelectual católico, padre, ligado à Companhia de Jesus e ao Institut Catholique de Paris, em periódico vinculado ao Centre d'Études Pédagogiques, é um fator relevante e corrobora o fato já aqui apontado de que existia, também, uma afluência de apropriação católica do movimento escolanovista.

De outra parte, auferir os espaços onde Luis Contier habitou na condição de produtor, publicando artigos a respeito da experiência brasileira e fazendo circular no contexto internacional o trabalho realizado no Brasil a partir de práticas e usos específicos das matrizes francesas, permite-nos perceber, também, o volume de seu capital intelectual, ao mesmo tempo em que lança luz sobre o fato de que os movimentos de circulação não ocorrem em um sentido único. Além disso, a movimentação de impressos em determinado campo veicula ideários, representações, indica formas de agir, tendo em vista que tais escritos estão investidos de significações plurais e móveis e comandam, não a imposição de um sentido, mas os usos e apropriações às quais é suscetível. (CHARTIER, 1994).

$\mathrm{Na}$ esteira dessas ações, podemos citar a publicação de Contier realizada no ano de 1967 na Revista Latinoamericana de Educación. Dividindo espaço com intelectuais norte e latino-americanos, o educador publica artigo "Una Experiencia Brasileña de Enseñanza Vocacional', no qual discorre acerca do cenário pós-Segunda Guerra Mundial e os projetos de reforma escolar que, postergados pelos anos da guerra, são apresentados nos países europeus, sobretudo França e Inglaterra, nesse período. (CONTIER, 1967). Destacamos o fato de que a presença de Contier como autor de textos publicados em periódicos de circulação internacional dá indícios de que esse educador fazia parte de uma rede de relações não apenas como consumidor do fluxo de informação nela disponível, mas também como produtor desses conteúdos. Ademais, tal presença o coloca como sujeito que possui um lugar social de destaque entre profissionais com autoridade nos campos educacionais de que fazia parte, o que the confere capital simbólico e intelectual - e, consequentemente, acaba por aumentar a rentabilidade dos demais volumes de capital que 
possuía, incluindo, aí, o capital social.

\section{Considerações finais}

Conclui-se que os laços estabelecidos por Contier em sua rede de relações figuravam como positivos, fortes e relativamente ativos. Positivos porque permitiam ao educador ser reconhecido entre os membros integrados àquela rede - ainda mais fortemente no contexto brasileiro. Nesse sentido, tendo sido legitimado por seus pares, tornou-se figura de autoridade e passou a ocupar cargos de prestígio, tais como o de diretor geral do Departamento de Educação do Estado de São Paulo, para o qual foi empossado no ano de abertura das Classes Experimentais Secundárias - fato que exerceu, também, influência positiva no que se referia à autorização das experiências. Seus laços eram também fortes, posto que, ainda que sem grau de intimidade relevante - até o ponto que as fontes consultadas permitiram auferir - trocava serviços com seus pares. São exemplos dessas trocas as situações nas quais solicitava a vinda de autoridades ao Brasil para as chamadas missões pedagógicas, ou quando levava profissionais brasileiros na condição de bolsistas para a realização de estágios no centro de Sèvres. Por fim, definimos aqui, como ativos, apenas os laços mantidos com o Consulado Geral Francês e com os intelectuais vinculados ao Centro Internacional de Estudos Pedagógicos (Ciep) de Sèvres no espaço-tempo recortado, uma vez que estes eram os únicos com os quais Contier mantinha contato regular por correspondência, fazendo parte do leque de laços de que poderia dispor se assim fosse necessário.

Como propõe Magalhães (2006), o processo de constituição da educação como objeto epistêmico deve estar articulado ao desvelamento das redes que o indivíduo integra, de maneira que o valor simbólico de sua produção intelectual é elemento fundamental a ser considerado. No caso de Contier, é preciso destacar que, apesar da riqueza de seus referenciais e a diversidade de seus escritos, há um ponto de aproximação com João Roberto Moreira, em consonância com o que apontou Xavier (2016): seus textos estavam apartados de uma produção acadêmica em ascensão no período, especialmente no estado de São Paulo, sediada no Departamento de Educação da Faculdade de Filosofia e Ciências e Letras da USP e, posteriormente, na Faculdade de Educação da mesma universidade. Seu vínculo com a instituição se deu em uma parceria pontual via CRPE-SP. Nesse sentido, gerou representações de decrescente valor simbólico no decorrer dos anos 1960, as quais foram gradativamente perdendo a notoriedade até então constatada. No entanto, aí entra a atuação do historiador, no sentido de desvelar uma narrativa que orientou não apenas uma perspectiva de renovação da educação antagônica a de Contier, mas promoveu um apagamento de sua figura como intelectual da educação.

Por tratar-se de ações, relações e processos voltados à divulgação e apropriação de uma matriz cunhada a partir de pressupostos e intelectuais ligados ao movimento da Escola Nova, que se constituiu como mundial e multifacetado, o objeto do presente estudo lança-nos, por si só, ao desafio do transnacional. Buscar ancorar tais ideias nas práticas dos sujeitos envolvidos e perceber a circulação da matriz das Classes Nouvelles - bem como os processos de renovação que tomaram forma a partir dessa apropriação inicial - a partir do trânsito e das redes sociais dos educadores brasileiros no eixo Brasil-Sèvres é uma das direções cujo investimento permite uma melhor compreensão dessas experiências. Observou-se, neste primeiro momento, que os movimentos de circulação aqui 
estudados não ocorreram em um sentido único. Os circuitos de viagens desses atores e o consequente tecer de suas redes de sociabilidades nos mostram como foram criadas mestiçagens no interior de uma geografia não uniforme. Perseguir esses trajetos, foi o que se intentou realizar no presente estudo. Caminhamos nessa direção com o intuito de compreender a tessitura desses ensaios pedagógicos e trazer ao cenário dos debates educacionais essas experiências renovadoras que, mesmo atualmente, já nos anos iniciais do século XX, não foram suficientemente investigadas. Pesquisas sobre o tema podem, sem dúvida, lançar luz sobre outros sujeitos e instituições que tiveram lugar de destaque nas redes aqui parcialmente explicitadas e, além disso, dar relevo a uma série de propostas de reformulação do ensino e flexibilização curricular que precederam os anos sombrios da ditadura militar. Integrantes de uma "tradição escolar (quase) esquecida" (DALLABRIDA, 2017) revelam-se, portanto, não apenas profícuos objetos de estudo a serem investigados, mas servem de referência para pensar historicamente o atual Ensino Médio, alvo de uma apressada tentativa de reforma pelo governo vigente, via Lei no 13.415 de 16 fevereiro de 2017, e atual Base Nacional Comum Curricular para o Ensino Médio, em processo de avaliação e aprovação.

\section{Referências}

AVELAR, Gersolina Antonia de. Renovação educacional católica. São Paulo: Cortez \& Moraes, 1978.

BOURDIEU, Pierre. Homo Academicus. Trad. Ione Ribeiro Valle e Nilton Valle. Rev. Maria Tereza de Queiroz Piacentini. 2 ed. Florianópolis: Editora da UFSC, 2013.

. O capital social - notas provisórias. In: NOGUEIRA, Maria Alice; CATANI, Afrânio (Orgs.). Escritos de Educação. Petrópolis, RJ: Vozes, 1998. p. 65-69.

BLOCH, March. Para uma história comparada das sociedades europeias. In:

História e historiadores. Lisboa: Teorema, 1948. p. 119-50.

BUZELLI FILHO, José. Coluna Universitária. [S.I] 12 maio 1961. Acervo Luis Contier: Centro de Memória da Educação da Universidade de São Paulo.

CARVALHO, Luís Miguel. Sobre a circulação do conhecimento educacional: três incursões. In: Ó, Jorge Ramos do; CARVALHO, Luís Miguel. Emergência e circulação do conhecimento psicopedagógico moderno (1880-1960): estudos comparados Portugal-Brasil. Lisboa: Educa, 2009. p. 155-94.

CERTEAU, Michel. A invenção do cotidiano. 1: Artes de fazer. Petrópolis: Vozes, 1994.

CHARTIER, Roger. A História Cultural. Entre práticas e representações. Lisboa: Difel, 1988.

A ordem dos livros: leitores, autores e bibliotecas na Europa entre os séculos XIV e XVIII. Trad. Mary Del Priore. Brasília: Editora Universidade de Brasília, 1994.

CHIOZZINI, Daniel Ferraz. As mudanças curriculares dos ginásios vocacionais de São Paulo: da "integração social" ao "engajamento pela transformação". Rev. Bras. Hist.

Educ., Maringá-PR, v. 14, n. 3[36], p. 23-53, set./dez. 2014.

CIUCHINI, Mário M. Classe experimental: revolução de 50 anos. Folha de São Paulo, São Paulo, 18 jun. 1962.

CONTIER, Luis. [Notas manuscritas de Luis Contier]. [S.I] [entre 1950 e 1970]. Acervo Luis Contier: Centro de Memória da Educação da Universidade de São Paulo. 
Luiz Contier: Introdutor das Classes Experimentais no Brasil. Entrevista. 04 fev. 1981. Acervo Luis Contier: Centro de Memória da Educação da Universidade de São Paulo.

Una experiencia brasileña de enseñanza vocacional. Revista Latinoamericana de Educación, La Plata, Buenos Aires, año X, n. 64, p. 324-332, jul./ago. 1967.

CUNHA, Maria Teresa Santos. Assim nas páginas como nas margens. Marcas do ler em livros escolares do acervo do Museu da Escola Catarinense (décadas de 20 a 70 do século XX). In: CONGRESSO BRASILEIRO DE HISTÓRIA DA EDUCAÇÃO, IV, 2006, Goiânia. Anais: A Educação e seus sujeitos na História... Goiânia:

SBHE/UCG/Goiânia, 2006. v. 01.

DANIEL, Leziany S. Roberto Moreira e o movimento pela escola nova em Santa Catarina (1934-1943). Revista Linhas, v. 10, n. 2, p. 181-207, jul./dez. 2009.

DALLABRIDA, Norberto. As classes secundárias experimentais: uma tradição escolar (quase) esquecida. Revista Brasileira de História da Educação, Maringá-PR, v. 17, n. 3[46], p. 213-234, jul./set. 2017.

O Mec-Inep contra a Reforma Capanema: renovação do Ensino Secundário na década de 1950. Perspectiva, Florianópolis, v. 32, n. 2, p. 407-427, maio/ago. 2014.

DOSSE, François. La marche des idees. Histoire des intellectuels - histoire intellectuelle. Paris: Éditions La Découverte, 2003.

FAURE, Pierre. Les progrès de la scolarisation et de l'enseignment au Brésil. Pedagogie: Education et culture, Centre d'Etudes Pédagogiques, Paris, França, p. 733-6, 1963.

INSTITUTO DE EDUCAÇÃO NARCISO PIERONI DE SOCORRO. Relatório de 1962. 1962. Acervo Maria Nilde Mascellani. Centro de Memória da Faculdade de Educação da Universidade de São Paulo.

LAWN, Martin. Um conhecimento complexo: o historiador da educação e as circulações transfronteiriças. Trad. Rafaela Silva Rabelo. Revista Brasileira de História da Educação, v. 14, n. 1[34], p. 127-44, 2014.

LIN, Nan. Social capital. A theory of social structure and action. Cambridge: Cambridge University Press, 2001a.

Building a network theory of social capital. In: ; COOK, Karen; BURT, Ronald S. (Orgs.). Social capital. Theory and research. New York: Aldine de Gruyter, 2001b. p. 3-29.

MAGALHÃES, Justino. Intelectuais e História da Educação em Portugal e Brasil.

Cadernos de História da Educação, v. 15, n. 1, p. 299-322, jan./abr. 2016.

MARQUES, Sandra Machado Lunardi. Contribuição ao estudo dos ginásios

vocacionais do Estado de São Paulo: o Ginásio Vocacional "Chanceler Raul

Fernandes" de Rio Claro. 1985. Dissertação (Mestrado em Filosofia da Educação) - PUCSP, São Paulo, 1985.

MASCELLANI, Maria Nilde. Um século de lutas pela liberdade. Diário Popular, 08 nov. 1984, p. 52. Acervo Gvive.

NOTÍCIA sobre a vinda de Mme. Lhotelier ao Brasil. Jornal Notícias Populares, São Paulo, 21 maio 1968. Centro de Memória da Educação da Faculdade de Educação da Universidade de São Paulo.

O RESGATE da memória: uma pedagogia em ato no cotidiano do vocacional. s.d. [entre 1960 e 1990]. Acervo Maria Nilde Mascellani: Centro de Memória da Educação da 
Faculdade de Educação da Universidade de São Paulo.

OFÍCIO n. 16. [solicita a instalação do $2^{\circ}$ ciclo ginasial no Ginásio Estadual Vocacional Oswaldo Aranha]. 8 set. 1967. Acervo Maria Nilde Mascellani: Centro de Memória da Educação da Faculdade de Educação da Universidade de São Paulo.

"PAl" do Experimental vem a Jundiaí no dia 14. Jornal de Jundiaí, Jundiaí, São Paulo, 14 out. 1980. Acervo Luis Contier: Centro de Memória da Educação da Faculdade de Educação da Universidade de São Paulo.

PORTUGAL, Silvia. Contributos para uma discussão do conceito de rede na teoria sociológica. Oficina do CES. 271 (2007), 36 p. Disponível em: <http://hdl.handle.net/10316/11097>. Acesso em: 1 jul. 2016.

PIAGET, Jean. Carta de Jean Piaget a Luiz Contier. São Paulo, 9 mai. de 1973. Acervo Luis Contier. Centro de Memória da Educação da Faculdade de Educação da Universidade de São Paulo.

ROCKWELL, Elsie. La apropiación, un proceso entre muchos que ocurren en ámbitos escolares. Memoria, conocimiento y utopia: anuário de la Sociedad Mexicana de Historia de la Educación, México, n. 1, p. 28-38, enero 2004/mayo 2005.

SAGVOA (SOCIEDADE AMIGOS DO GINÁSIO VOCACIONAL OSWALDO ARANHA). Boletim n. 01. Março de 1966. Acervo Maria Nilde Mascellani: Centro de Memória da Educação da Faculdade de Educação da Universidade de São Paulo.

SIRINELLI, Jean-François. Os intelectuais. In: RÉMOND, René (Org.). Por uma história política. Rio de Janeiro: FGV, 2003. p. 231-270.

TAMBERLINI, Ângela Rabello Maciel de Barros. Os Ginásios Vocacionais, a História e a possibilidade de futuro. In: Cortez, 2005. p. 15-24. Ensino vocacional: uma pedagogia atual. São Paulo:

TEIXEIRA, Anísio. Educação não é privilégio. 7 ed. Rio de Janeiro: UFRJ, 2007.

TERMO de abertura do livro das atas do Conselho Executivo do Centro de Estudos Pedagógicos de São Paulo. São Paulo, 13 jul. 1965. Acervo Luis Contier: Centro de Memória da Educação da Universidade de São Paulo.

VIEIRA, Carlos Eduardo. Intelligentsia e intelectuais. Sentidos, conceitos e possibilidades para a história intelectual. Revista Brasileira de História da Educação, v. 8, n. 1 (16), 2008.

VIEIRA, Letícia. Um núcleo pioneiro na renovação da educação secundária brasileira: as primeiras Classes Experimentais do estado de São Paulo (1951-1961). 2015. 200 f. Dissertação (Mestrado em Educação) - Centro de Ciências Humanas e da Educação, Universidade do Estado de Santa Catarina/Udesc, 2015.

VOGT, Carlos. A espiral da cultura científica. ComCiência: Revista Eletrônica de Jornalismo Científico, n. 45, jul. 2003. Disponível em:

<http://www.comciencia.br/reportagens/cultura/cultura01.shtml>. Acesso em: 25 jun. 2017.

WASSERMAN, Stanley; FAUST, Katherine. Social network analysis. Methods and applications. Cambridge: Cambridge University Press. 1999. Disponível em:

<http://www.asecib.ase.ro/mps/Social\%20Network\%20Analysis\%20[1994].pdf>. Acesso em: 14 jun. 2016.

XAVIER, Libânia Nacif. Interfaces entre a história da educação e a história social e política dos intelectuais: conceitos, questões e apropriações. In: GOMES, Angela de Castro; HANSEN, Patrícia dos Santos (Orgs.). Intelectuais mediadores: práticas culturais e acão política. 1 ed. Rio de Janeiro: Civilização Brasileira, 2016. v. 1, p. 464-486. 
LETÍCIA VIEIRA é doutoranda no Programa de Pós-Graduação em Educação da Faculdade de Educação da Universidade de São Paulo (USP) e mestre em Educação pela Universidade do Estado de Santa Catarina (Udesc).

Endereço: Rua Venidiomar Krug, 36, Estreito, Florianópolis/SC, Brasil.

E-mail: leticia.vieira1990@gmail.com

DANIEL FERRAZ CHIOZZINI é professor do Programa de Estudos Pós-Graduados em Educação: História, Política, Sociedade da Pontifícia Universidade Católica de São Paulo (PUC-SP), onde também realizou pós-Doutoramento. Integra a linha de pesquisa "Educação Brasileira: produção, circulação e apropriação cultural" e é um dos líderes do grupo de Pesquisa "História das Instituições e dos Intelectuais da Educação Brasileira".

Endereço: Rua Alexandre Benois, 17 - ap. 103 B, São Paulo/SP, Brasil.

E-mail: danielchiozzini@yahoo.com.br

Recebido em 26 de fevereiro de 2018.

Aceito em 03 de julho de 2018. 